\title{
ИСТОРИЯ ПРАВА
}

В.Ю. Маркин

\section{ПОРЯДОК И ОСОБЕННОСТИ ФОРМИРОВАНИЯ КАДРОВОГО СОСТАВА СУДЕБНЫХ ИСПОЛНИТЕЛЕЙ ПОСЛЕ СУДЕБНОЙ РЕФОРМЫ 1922 г.}

\begin{abstract}
Аннотация: Органы принудительного исполнения судебных решений, как одни из важнейших звеньев государственного механизма, прошли долгий путь становления и развития. Одним из знаменательных моментов Россий-ской истории, кардинально повлиявшим, в частности, на институт судеб-ного исполнения, была судебная реформа 1922 г., которой была фактически уч-реждена единая система органов судебного исполнения с принципиально новыми организационными началами их деятельности. Это отразилось и на проиессе формирования кадрового состава судебных исполнителей, и на выработке государственной политики в отношении последних. Однако, данный момент не получил должного освещения в отечественной юриди-ческой науке, в связи с чем возникла необходимость проведения соответствующего исследования с иелью построения наиболее полной и достоверной историко-правовой картины тех лет в части организации и деятельности отечественных судебно-исполнительных органов.
\end{abstract}

Ключевые слова: Юриспруденция, суд, исполнитель, кадры, состав, набор, уезд, губерния, развитие, Россия

$\longrightarrow$

ореформенный период развития России выявил несостоятельность методов управления народным хозяйством, свойственных политике военного коммунизма. Окончание гражданской войны обусловило необходимость отказа от реализации чрезвычайных средств и методов управления, применение которых в условиях мирной жизни было нерациональным. Государством был взят курс на реализацию новой экономической политики ${ }^{1}$. Такого рода преобразования были тесным образом связаны с необходимостью всецелой переработки системы судебных учреждений, которая с одной стороны, являлась гарантом соблюдения и реализации государственной идеологии, с другой стороны - действенным инструментом защиты государственных интересов²

\footnotetext{
${ }^{1}$ Декрет ВЦИК РСФСР от 21 марта 1921 г. «О замене продовольственной и сырьевой разверстки натуральным налогом» // Собрание узаконений РСФСР. 1921. № 26. Ст. 147.

2 Портнов В.П., Славин М.М. Становление правосудия Советской России. 1917-1922. М., 1989. С. 80-82.
}

Изменившиеся социальные условия жизни и труда, несовершенство правоприменительной практики, наличие большого массива несистематизированного нормативного материала и многочисленные законодательные пробелы ${ }^{3}$ обосновали решительность в выборе подхода к изменению правовой сферы жизнедеятельности государства и общества.

31 октября 1922 г. IV сессией ВЦИК РСФСР было одобрено и принято Положение «О судоустройстве РСФСР» (далее - Положение 1922 г.), которым была сформирована единая трехзвенная система судов. Согласно ст. 1 Положения 1922 г. на территории РСФСР система судебных учреждений состояла из следующих звеньев: народный суд в составе постоянного народного судьи; народный суд в составе постоянного народного судьи и двух

\footnotetext{
${ }^{3}$ См.: Брыжинская Е.В. Судебная реформа 1922 г. и особенности развития судов в условиях новой экономической политики // Социальные и гуманитарные исследования: традиции и реальности. Межвузовский сборник научных трудов. Саранск, 2005. Вып. 4. С. 86.
} 


\section{Политика и общество 1 (97) • 2013}

народных заседателей; губернский суд; Верховный суд РСФСР и его коллегии. Также была предусмотрена и система специализированных судебных учреждений: военные трибуналы по делам о преступлениях, угрожающих крепости и мощи Красной армии; особые трудовые сессии народных судов по делам о нарушении норм Кодекса законов о труде (далее - КЗоТ); местные и центральные арбитражные комиссии по рассмотрению экономических споров.

Однако подобная рационализация структуры судебных учреждений в свою очередь требовала создания действенной и стройной системы исполнительных органов, устранения их прежнего многообразия и создания достаточного нормативного обеспечения их деятельности.

Первым шагом к достижению данных целей было официальное закрепление на общегосударственном уровне в исходном судоустройственном акте республики (Положении 1922 г.) органов принудительного исполнения - судебных исполнителей, которые учреждались при губернских и народных судах ${ }^{4}$.

Не определив других исполнительных органов, законодатель фактически наделил судебных исполнителей исключительной компетенцией в сфере принудительного исполнения, что может свидетельствовать о попытке типизации исполнительных органов.

Наряду с этим, реорганизации подвергся ранее применявшийся ${ }^{5}$ (до 1922 г.) порядок формирования кадрового состава судебных исполнителей, а именно была скорректирована процедура поступления на службу и пересмотрена кадровая политика в отношении последних.

Процедура поступления на службу в качестве судебного исполнителя после судебно-правовых преобразований 1922 г. выглядела следующим образом. Первый вариант - подача заявления заинтересованным лицом уполномоченному губернского суда определенного уезда (далее - уполномочен-

\footnotetext{
${ }^{4}$ Постановление ВЦИК РСФСР от 11 ноября 1922 г. «О введении в действие положения о судоустройстве РСФСР» // Собрание узаконений РСФСР. 1922. № 69. Ст. 902.

${ }^{5}$ См., подробнее: Маркин В.Ю. О некоторых частных аспектах организации судебных исполнителей в первые годы советской власти (на примере Курской губернии 1917-1921 гг.) // Право и политика. 2012. № 12. С. 2050-2053.
}

ный). Уполномоченные являлись связующими звеньями между губернскими судебными центрами и уездными судебными учреждениями и органами юстиции $^{6}$, и выступали в качестве органа первичного контроля и руководства на местах.

В заявлении содержалось волеизъявление лица быть зачисленным на службу судебным исполнителем. Обязательно указывалось предыдущее место (места) работы и сроки работы с конкретизацией периодов. К заявлению прилагалась анкета, содержание которой практически полностью соответствовало содержанию анкеты, введенной в правовой оборот еще до 1922 г. Основное отличие между этими документами состояло в том, что после 1922 г. анкеты стали издаваться по установленной форме с указанием конкретного уезда, Ф.И.О. уполномоченного, его подписью и печатью, т.е. были облечены в строгую форму. Заполненная анкета и заявление представлялись уполномоченному либо нарочным, либо почтовым способами. После получения документов уполномоченный самостоятельно выполнял первичную проверку предоставленной информации, т.е. иными словами, удостоверялся в подлинности наиболее простых в плане проверки фактов (Ф.И.О., год рождения, семейное положение, образование и.т.п.). За умышленное сообщение в анкете ложных сведений виновное лицо подлежало уголовной ответственности ${ }^{7}$.

Если ранее (до 1922 г.) в процессе поступления на службу политико-идеологические воззрения претендента играли практически ведущее значение, то в рассматриваемом периоде уполномоченные должностные лица все больше внимания обращали на профессиональные качества потенциально возможного работника. По большей степени это объяснялось, во-первых, нехваткой компетентных судебно-исполнительных кадров, во-вторых, целями проведенной судебно-правовой реформы, одной из которой было повышение качества правосудия и эффективности работы отдельных категорий служащих. Вопросы отношения претендента к государственной идеологии и политике государства разрешались специальными органами, а именно соответствующими отделами Народного комиссариа-

\footnotetext{
${ }^{6}$ Государственный архив Белгородской области (далее ГАБО). Ф. Р424. Справочно-информационный лист ОП. №1.

${ }^{7}$ Государственный архив Курской области (далее - ГАКО). Ф. Р166. ОП. 1-Л. Д. 19. Л. 4-12.
} 
История права

та внутренних дел РСФСР (далее - НКВД РСФСР) или в порядке секретных заседаний президиумов уездных исполнительных комитетов ${ }^{8}$.

Следующим этапом процедуры назначения было составление уполномоченным «отношения». Суть данного документа не изменилась. Как

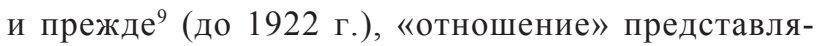
ло собой документ, в котором излагалось содержание самого заявления. Единственным нововведением было содержание в «отношении» мнения уполномоченного относительно кандидатуры претендента на должность судебного исполнителя. Хотя это было скорее небольшой условностью, и даже если уполномоченный приводил в «отношении» негативные доводы, это не исключало дальнейшего движения дела. Документ в обязательном порядке направлялся для рассмотрения в уездный исполнительный комитет.

После поступления «отношения» начальник уездного исполнительного комитета назначал дату и время заседания президиума для рассмотрения вопроса о допуске кандидата на должность к вступительным испытаниям в губернском суде, проводимых в форме экзамена. По окончании заседания составлялся протокол, и выписка с его резолютивной частью направлялась в губернский суд. Если исполнительным комитетом выносилось решение не в пользу кандидата на должность, то дальнейшее движение дела исключалось.

Следующая стадия - производство по вопросу назначения в губернском суде. Этот этап характеризуется необходимостью прохождения экзамена на соответствие предъявляемых требований уровню правовых знаний испытуемого и непосредственное решение вопроса о назначении на желаемую должность. Заметим, что как и прежде суду отводилась второстепенная роль по отношению к органам исполнительной власти, в частности, к уездному исполнительному комитету. Ведь в случае, если исполнительный комитет выносил отрицательное решение в отношении кандидата, то возможность оспаривания такого решения у противной стороны отсутствовала. Также не мог губернский суд и напрямую решить вопрос о назначении, минуя уездный исполнительный комитет. Это обуславливалось тем, что местные органы ис-

${ }^{8}$ ГАКО. Ф. Р166. ОП. 1. Д. 49. Л. 18, 34, 36-38.

${ }^{9}$ См.: Маркин В.Ю. Указ. соч. С. 2050-2053. полнительной власти представляли собой основу для всей системы государственного управления того времени и являлись проводниками в реализации политики центральных органов власти, которыми был взят курс на ужесточение государственного контроля практически за всеми сферами жизни общества ${ }^{10}$. В свою очередь Народный комиссариат юстиции РСФСР (далее - НКЮ РСФСР) путем проведения экзаменов осуществлял кадровую политику в отношении всех работников судебных учреждений и органов юстиции ${ }^{11}$.

В сравнении с дореформенным периодом (имеется в виду реформа 1922 г.) законодательно были установлены четкие требования к кандидатуре судебного исполнителя. Согласно Циркуляру НКЮ РСФСР № 213 от 11.10.1923 г. испытуемый на должность судебного исполнителя должен был продемонстрировать навыки владения следующими областями юридического знания: основ судоустройства, гражданского и уголовного права, гражданско-процессуального и уголовно-процессуального права, исполнительного производства ${ }^{12}$. Экзамен проводился в губернском суде и организовывался комиссией из числа ответственных работников. Как правило, в комиссию входили заместитель председателя, судьи и судебные исполнители губернского суда. В некоторых случаях участие принимал и уполномоченный. Критерии оценки знаний испытуемого нормативно закреплены не были. Представляется, что их оценка производилась комиссией исходя из общих требований разумности и фактическим уровнем владения кандидатом юридического материала.

После сдачи экзамена составлялся протокол, который приобщался к личному делу. Прохождение квалификационных испытаний означало принятие на службу и зачисление в штат губернского суда. После этого, определенное количество судебных исполнителей (по общему правилу один судебный ис-

${ }^{10}$ Кара-Мурза С.Г. История советского государства и права. M., 1996. С. 309.

${ }^{11}$ Декрет ВЦИК РСФСР от 01 февраля 1923 г. «Положение о Народном комиссариате юстиции» // Собрание узаконений РСФСР. 1923. № 10. Ст. 120

12 Циркуляр НКЮ РСФСР от 11 октября 1923 г. № 213 «О требованиях, предъявляемых при производстве испытаний кандидатов на должности в органах юстиции» // Сборник циркуляров НКЮ РСФСР за 1922-1925 гг. (действующих по состоянию на 15 июля 1926 г.). М., 1926. С. 19-20. 


\section{Политика и общество 1 (97) • 2013}

полнитель на один уезд) подлежало распределению по конкретным участкам народных судов губернии и в штатный состав последних они не входили ${ }^{13}$.

Второй вариант поступления на службу - не подача заявления заинтересованным лицом уполномоченному конкретного уезда, а самостоятельные действия последнего по изысканию потенциальных кандидатов. Данный вариант носил скорее ситуативный характер и применялся при необходимости учреждения в уезде дополнительной должности судебного исполнителя ${ }^{14}$.

Процедура введения дополнительной должности судебного исполнителя начиналась с рассмотрения вопроса о целесообразности такой меры на заседании пленума губернского суда с последующим составлением протокола. Пленум, признав необходимым учреждение должности второго судебного исполнителя, направлял копию протокола в административно-хозяйственное управление, а именно заведующему частью личного состава губернского суда. Заведующий частью личного состава издавал письменное распоряжение уполномоченному губернского суда о необходимости осуществления надзора за исполнением предложения губернского суда о выставлении кандидатуры на второго судебного исполнителя ${ }^{15}$.

Уполномоченным проводились мероприятия по изысканию лиц, желающих быть зачисленными на службу. Для этого он направлял в различного рода уездные государственные учреждения юстиции сообщения об объявлении конкурса на должность судебного исполнителя следующего содержания «... объявляется конкурс на занятие должности судебного исполнителя «наименование уезда». По всем возможным вопросам и предложениям обращаться в камеру вашего судебного уполномоченного...» ${ }^{16}$. В случае, если на сообщение откликалось не одно, a несколько лиц, уполномоченный принимал от них необходимые документы и впоследствии составлял несколько «отношений».

Затем он направлял «отношения» в соответствующий уездный исполнительный комитет. На

${ }^{13}$ ГАКО. Ф. Р166. ОП. 1-Л. Д. 17. Л. 17, 19, 20, 23-25.; ОП. 1. Д. 256. Л. 41.; ОП. 1. Д. 28. Л. 5-6.; ГАБО. Ф. Р424. ОП. 2. Д. 114. Л. 11-12.

${ }^{14}$ ГАБО. Ф. Р424. ОП. 2. Д. 114. Л. 1, 3, 11.

${ }^{15}$ ГАБО. Ф. Р424. ОП. 2. Д. 114. Л. 2.

${ }^{16}$ Там же. Л. 9. заседании члены президиума выбирали наиболее грамотного и компетентного работника из числа представленных соискателей. Предпочтения отдавались лицам, имевшим стаж юридической работы. Если среди кандидатов были лица, какимто образом связанные со сферой принудительного исполнения (к примеру, если они работали судебными приставами царской России), то фактически их преимущества перед другими были неоспоримыми и, как правило, их утверждали на соответствующие должности без проведения иных формальных процедур.

Здесь стоит отметить, что по сравнению с дореформенным периодом (до 1922 г.) государственная политика в отношении лиц, работавших при царском режиме, стала более лояльной и не столь критичной. По всей видимости, властью было осознано, что подготовка и переподготовка работников юстиции процесс долгий и весьма дорогостоящий и пренебрегать фактически уже готовыми кадрами было нерационально.

Важной особенностью такого способа назначения состоит в том, что претендент не проходил вступительные испытания в губернском суде. Его навыки и умения оценивали члены президиума ввиду того, что некоторые волости и уезды располагались на значительно удаленном расстоянии от губернского центра, а в совокупности с непривлекательностью профессии судебного исполнителя ${ }^{17}$ это и привело к возникновению данного порядка.

После квалификационной аттестации президиум уездного исполнительного комитета принимал решение об утверждении (либо об отказе в утверждении) кандидатуры на должность судебного исполнителя. После утверждения на должность протокол (или выписка, содержащая резолютивную часть) направлялись в губернский суд, где председателем издавался соответствующий приказ о назначении лица на должность судебного исполнителя ${ }^{18}$.

Резюмируя вышеизложенное, хотелось бы сказать следующее. Судебно-правовая реформа 1922 г. в сущности, открыла новую страницу не только в истории отечественного правосудия, но и органов принудительного исполнения. Впервые после октябрьских событий 1917 г. в

\footnotetext{
${ }^{17}$ Крамоновский К. Процессуальные аспекты исполнения судебных решений. Одесса, 1928. С. 40.

${ }^{18}$ ГАБО. Ф. Р424. ОП. 2. Д. 114. Л. 1, 10.
} 
России начала функционировать полноценная и весьма результативная система судебных учреждений, а вместе с ней и система органов судебного исполнения. Конечно, нельзя идеализировать результаты реформационного процесса. Но, рассматривая их применимо к органам принудительного исполнения, можно констатировать тот факт, что некоторые негативные моменты свойственные дореформенному периоду, в частности, процесса формирования кадрового состава судебных исполнителей в целом были устранены. Были пересмотрены и организационные моменты процедуры поступления на должность судебного исполнителя и, что немаловажно, скорректирован курс государственной политики в отношении органов судебного исполнения. Таким образом, в совокупности данными обстоятельствами были созданы дополнительные предпосылки для улучшения организационных основ и функционирования органов принудительного исполнения в РСФСР.

\section{Библиография:}

1. Декрет ВЦИК РСФСР от 21 марта 1921 г. «О замене продовольственной и сырьевой разверстки натуральным налогом» // Собрание узаконений РСФСР. 1921. № 26. Ст. 147.

2. Портнов В.П., Славин М.М. Становление правосудия Советской России. 1917-1922. М., 1989. С. 80-82.

3. Брыжинская Е.В. Судебная реформа 1922 г. и особенности развития судов в условиях новой экономической политики // Социальные и гуманитарные исследования: традиции и реальности. Межвузовский сборник научных трудов. Саранск, 2005. Вып. 4. С. 86.

4. Постановление ВЦИК РСФСР от 11 ноября 1922 г. «О введении в действие положения о судоустройстве РСФСР» // Собрание узаконений РСФСР. 1922. № 69. СТ. 902.

5. Маркин В.Ю. О некоторых частных аспектах организации судебных исполнителей в первые годы советской власти (на примере Курской губернии 1917-1921 гг.) // Право и закон. 2012. № 12 . С. 2050-2053.
6. ГАБО. Ф. Р424. Справочно-информационный лист ОП. №1.

7. ГАКО.Ф. Р166. ОП. 1-Л. Д. 19. Л. 4-12.

8. ГАКО. Ф. Р166. ОП. 1. Д. 49. Л. 18, 34, 36-38.

9. Кара-Мурза С.Г. История советского государства и права. М., 1996. С. 309.

10. Декрет ВЦИК РСФСР от 01 февраля 1923 г. «Положение о Народ-ном комиссариате юстиции» // Собрание узаконений РСФСР. 1923. № 10. Ст. 120.

11. Циркуляр НКЮ РСФСР от 11 октября 1923 г. № 213 «О требовани-ях, предъявляемых при производстве испытаний кандидатов на должности в органах юстиции» // Сборник циркуляров НКЮ РСФСР за 1922-1925 гг. (действующих по состоянию на 15 июля 1926 г.). М., 1926. С. 19-20.

12. ГАКО. Ф. Р166. ОП. 1-Л. Д. 17. Л. 17, 19, 20, 23-25.; ОП. 1. Д. 256. Л. 41.; ОП. 1. Д. 28. Л. 5-6.; ГАБО. Ф. Р424. ОП. 2. Д. 114. Л. 11-12.

13. ГАБО. Ф. Р424. ОП. 2. Д. 114. Л. 1, 3, 1

14. ГАБО. Ф. Р424. ОП. 2. Д. 114. Л. 2, 9.

15. Крамоновский К. Процессуальные аспекты исполнения судебных решений. Одесса, 1928. С. 40.

16. ГАБО. Ф. Р424. ОП. 2. Д. 114. Л. 1, 10.

\section{References (transliteration):}

1. Portnov V.P., Slavin M.M. Stanovlenie pravosudiya Sovetskoy Ros-sii. 1917-1922. M., 1989. S. 80-82.

2. Bryzhinskaya E.V. Sudebnaya reforma 1922 g. i osobennosti razvitiya sudov v usloviyakh novoy ekonomicheskoy politiki // Sotsial'nye i gumanitarnye issledovaniya: traditsii i real'nosti. Mezhvuzovskiy sbornik nauchnykh trudov. Saransk, 2005. Vyp. 4. S. 86.

3. Markin V.Yu. O nekotorykh chastnykh aspektakh organizatsii sudebnykh ispolniteley $\mathrm{v}$ pervye gody sovetskoy vlasti (na primere Kurskoy gubernii 1917-1921 gg.) // Pravo i zakon. 2012. № 12. S. 2050-2053.

4. Kara-Murza S.G. Istoriya sovetskogo gosudarstva i prava. M., 1996. S. 309.

5. Kramonovskiy K. Protsessual'nye aspekty ispolneniya sudebnykh resheniy. Odessa, 1928. S. 40. 